\title{
Research on Standardization of College Student Volunteer Service System
}

\author{
Wenbin Liu \\ College of Science \\ Yanbian University \\ Yanji, China
}

\begin{abstract}
After entering the 21st century, China's volunteer service team and quality of volunteer service have been significantly improved. The current college students volunteer service work also highlights the problems, such as a single, volunteer work ability in volunteer service contents, service motive is not clear, lack of volunteer service organization guarantee and so on, affecting the sustainable development of the college students volunteer service. There is an urgent need to take effective measures to establish standardized work of college students' volunteer service system.
\end{abstract}

Keywords-college students; volunteer service; measures; the canonical

\section{INTRODUCTION}

Voluntary service not only inherits and carries forward the traditional virtues of the Chinese nation, but also sets up a new atmosphere in the new era. It becomes an effective carrier of mass spiritual civilization construction in the new era and plays an important role in improving social progress. Young college students have a high level of knowledge and culture, active thinking, positive and willing to contribute, and can form a positive social culture through demonstration and driving role in the process of volunteer service, which is conducive to further improving the social atmosphere and purifying the social environment. However, with the gradual increase of the number of people involved in volunteer work, some disharmonious problems have become prominent, affecting the sustainable and harmonious development of college students' volunteer work.

\section{PRoblems EXISTING IN THE VOLUNTEER SERVICE OF COLLEGE STUDENTS IN CHINA}

\section{A. College Students' Volunteer Work Is Not Rich Enough}

At present, all college students volunteer service work plays a more and more important role in the social public welfare activities, such as the community volunteer service, volunteer service work in large-scale activities, performing programs for the aged in nursing homes, donations, handbill distribution on "International Consumer Rights Day", etc. The volunteer service generally has a common defect, like the content of these volunteer services is lack of diversity and innovation, and it is basically impossible to give full play to students' professional knowledge and skills. On the other hand, the professional characteristics of volunteer learning are not obvious, which cannot meet the requirements of the new era on the cultivation of innovative consciousness.

\section{B. Volunteer Public Service for College Students}

College students are in the stage of transition from school to society at this stage. Their analysis and control of some problems are not very accurate. On some issues, they lack correct ideological and moral understanding. This makes them maintain high enthusiasm in the initial stage of volunteer service. However, once they find that volunteer service cannot reach the expected goal, they are likely to suffer from impetuous, contradictory psychology and loss of service enthusiasm. Undeniably, there is another situation, a considerable part of the motivation of college students to participate in volunteer service work mainly includes the following utilitarian tendencies such as evaluation of scholarships, excellent and advanced student cadre evaluation, competition, to join the party. These tendencies hindering the students actively join in volunteer activities, seriously affecting the effect of voluntary service.

\section{Lack of Volunteer Service Ability of College Students}

Although college students have mastered certain scientific and cultural knowledge, their knowledge level only exists in the research of professional knowledge. Most students do not know how to deal with the problems in social service and volunteer work in the process of social practice. In view of this situation, the organizers of voluntary service will organize relevant short-term training, but the short-term training before each activity cannot make up for the lack of professional knowledge and methods fundamentally, leading to the failure of many voluntary service activities. At the same time, especially in the aspects of safety prevention and emergency management, the knowledge reserve and ability experience of college student volunteers are obviously insufficient. Sometimes, they are caught unprepared and prone to panic, and even some safety accidents may occur in serious cases.

\section{There Is No Organizational Guarantee Mechanism for College Students' Volunteer Service}

The author has learned that the volunteer service teams of colleges and universities are organized and managed by the youth league committee of the university and the youth league committee of each secondary college. Due to the insufficient staffing of youth league committees at all levels and the large daily workload, college students' volunteer service lacks 
perfect management to some extent, making it difficult to form a standardized volunteer service team, which also causes great difficulties for the standardization process of college students' volunteer service system. In addition, a very important reason is that college students' voluntary service funds cannot be guaranteed. There is no clear funding plan, and the channels and number of self-financing funds are limited, which also leads to the corresponding decline in the quality of voluntary service activities.

\section{TAKING EFFECTIVE MEASURES TO PROMOTE THE STANDARDIZATION OF COLLEGE STUDENTS' VOLUNTEER SERVICE SYSTEM}

\section{A. Combining College Students' Professional Volunteer Knowledge, Innovating Volunteer Service Content}

In order to enable college students with certain professional knowledge to participate in professional volunteer activities, a variety of volunteer service projects are carried out. In this way, not only can the quality of volunteer service activities be improved, but also the professional knowledge learned by volunteers can be applied to real life to improve the professional skills of college students. At the same time, it's needed to combine with the school running characteristics, innovate volunteer service content, increase some volunteer service, professional skills, expand the field of college students volunteer service, which not only avoids the single volunteer situation, also takes advantage of the college students' professional to makes students have more love towards their major, let college students truly feel the charm and fun of volunteerism.

\section{B. Correcting the Motivation and Attitude of College Students' Voluntary Service Work}

In order to correct the motivation of college students' volunteer service, it is necessary to establish a strict volunteer selection system. When the whole society are vigorously carry forward the spirit of voluntary service at the same time, universities should attach great importance to the volunteer service work, pay attention to the education investment, in the aspect of volunteer service to the college student volunteers to instill positive volunteerism, encourage college students to participate in volunteer activities, let them be enthusiastic about volunteer work and have a correct understanding, correct all unhealthy tendencies from the source and establish a clean and healthy environment for volunteer service. Secondly, colleges and universities can report volunteer activities through traditional media and Internet media, pay attention to building the image of advanced volunteers, actively publicize the volunteer spirit of excellent volunteers, and use the power of role models to subtly influence the service motivation and attitude of students' volunteers.

\section{Improving College Students' Volunteer Service Ability}

Relevant departments of colleges and universities should clarify their respective responsibilities as soon as possible, take the lead from designated departments, formulate a unified management system, so as to effectively lead and manage college volunteer teams, and coordinate the development of college volunteer activities, so that college volunteer activities can be carried out in an orderly manner. Colleges and universities should also attach great importance to the early training of volunteer activities, set up special training institutions, provide specific and targeted guidance to volunteer teams, and carry out corresponding training in etiquette, professional skills, management ability and other aspects. Take the initiative to help college students design their plans before they volunteer to participate in daily activities, put forward the proposal, at the same time in the process of volunteer service work to correct mistakes in time, at the end of the volunteer service activities to guide college students volunteer in a timely manner, to build the management mode, so as to realize the management of the volunteer team specialization.

\section{Establishing an Organizational Guarantee Mechanism for College Students' ${ }^{\prime}$ Volunteer Service}

A scientific and standardized organization and management mechanism should be established. Universities choose enthusiastic public welfare undertakings and dedicated mentors to provide special guidance for the association, establish and improve the volunteer service training system for college students, and strive to improve the volunteer service ability of students. Schools should carry out social practice activities with college students' voluntary service as the main content. Providing opportunities for college students to volunteer work and giving them credit according to the service effect. Really achieve a good combination of classroom teaching and extracurricular practice more can stimulate the enthusiasm of students join the volunteer team. Schools should also strengthen the construction of volunteer service base for college students, forming a series of volunteer service brand projects. In addition, special personnel are arranged in the youth league committees at all levels for management to ensure the orderly development of volunteer services for college students.

\section{E. Attracting Investment of Off-campus Resources and Strengthening School-enterprise Cooperation}

While providing certain funds for voluntary service, colleges and universities should raise more funds through the society. Colleges and universities can use high-quality volunteer service programs to attract corporate sponsorship, which can not only solve the problem of lack of funds for voluntary organizations, but also help enterprises improve their social reputation and influence. For this, collecting volunteer projects within schools is very important. Firstly, volunteer teams submit detailed planning books, and then teachers review of the projects, organizing volunteer teams to defend their projects and choose several excellent volunteer service projects and finally inviting company representatives to participate in the defense of excellent volunteer service projects The company can provide the corresponding support. In addition, when the volunteer service project is carried out, all kinds of media of the school should carry out reports to expand the influence of volunteer service, let more enterprises pay attention to the volunteer service of college students, and strive to get more financial support. 


\section{F. Establishing Assessment and Incentive Mechanism}

Schools can create a website with information about volunteering. On this website, volunteer activities can be published to recruit volunteers, information collection can be carried out on recruited volunteers, supervision can be carried out on volunteer work, and the completion effect of volunteers in the service process can be recorded. Multi-angle information input can also correctly evaluate volunteer work. Although college students volunteer service itself has strong volunteer properties, organizers can give corresponding recognition at the end of each volunteer service or when the school awards honorary certificates every year to satisfy volunteers and the volunteers also can realize their self-worth in order to create a good atmosphere of volunteer service, cultivating college students volunteer service consciousness, promote the vigorous development of volunteer activities.

\section{CONCLUSION}

Through effective measures to standardize the volunteer service system of college students, it can strengthen and improve the ideological and political education of college students, enhance the effectiveness of education. By standardizing college students' volunteer service activities, a long-term mechanism of college students' volunteer service can be established, which can enrich the means of ideological and political education and the channel of social practice in colleges and universities. Giving full play to the carrier role of voluntary ideological and political education can effectively enhance the effectiveness of ideological and political education. Volunteer service will be included in classroom teaching and extracurricular practice, and volunteer service activities will be used for a long time to enrich the content of College Students' social practice. Through self-education, practical education, self-motivation and other forms of comprehensive education for volunteers. Improve the overall quality of volunteers, so that they can establish a correct world outlook, outlook on life and values.

\section{REFERENCES}

[1] Y. Zhou, Selection and Application of Ideological and Political Education Carrier for College Students, Research on Ideological and Political Education, vol. 3, 2007, pp.55-58.

[2] Y. Liu, Failure of College Students' Volunteer Service and Establishment of Correction Institutions, Research on Contemporary Youth, vol. 3, 2016, pp.33-38.

[3] M. Su, Thoughts on Building a Long-term Mechanism of College Students' Volunteer Service, Modern Economic Information, vol. 10, 2016, pp.425.

[4] J. Dai, Research on Standardization of College Student Volunteer Service System, Journal of Henan Mechanical and Electrical College, vol. 25, 2017, pp.28-31.

[5] H. Wang, Problems and Solutions of College Volunteer Service, Green Technology, vol. 17, 2018, pp.270-271. 